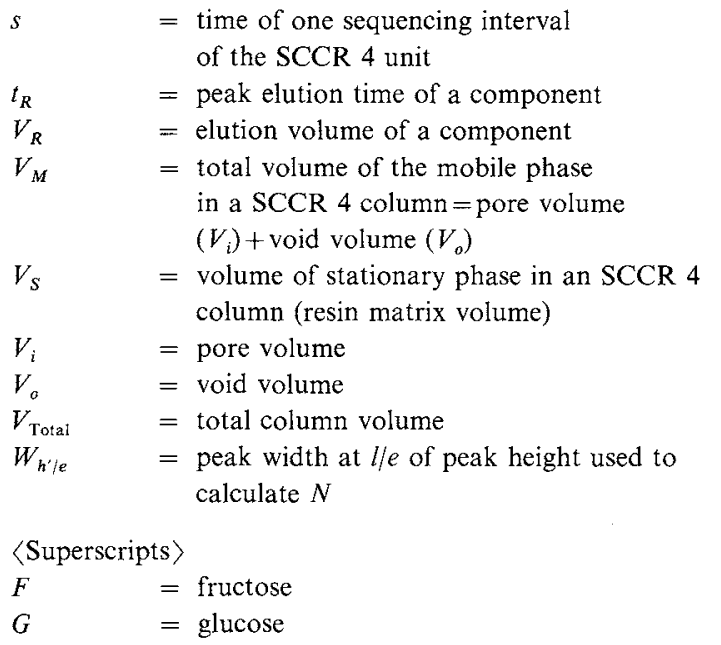

\begin{tabular}{|c|c|c|}
\hline \multicolumn{3}{|c|}{ Literature Cited } \\
\hline $\begin{array}{l}{[\min ]} \\
{[\mathrm{min}]} \\
{\left[\mathrm{cm}^{3}\right]}\end{array}$ & 1) & $\begin{array}{l}\text { Baker, P. E. and C. B. Ching: Kemtek } 5 \text { th International } \\
\text { Congress on Chemical Engineering European Federation of } \\
\text { Chemical Engineering, Copenhagen, April } 1980 .\end{array}$ \\
\hline & 2) & $\begin{array}{l}\text { Barker, P. E. and C. H. Chuah: The Chemical Engineer, U. } \\
\text { K., Aug./Sept., } 1981 \text {. }\end{array}$ \\
\hline & 3) & $\begin{array}{l}\text { BMA Process Pamphlet by Boehringer Mannhium GmbH, } \\
1968 \text {. }\end{array}$ \\
\hline $\mathrm{m}$ & 4) & $\begin{array}{l}\text { Boehringer, C. F. and Soehme GmbH: Brit. Patent } 1085696 \text {, } \\
\text { Oct., } 1967 .\end{array}$ \\
\hline$\left[\mathrm{cm}^{3}\right.$ & 5) & Broughton, D. B.: Chem. Eng. Progr., 64, 60 (1968). \\
\hline & 6) & $\begin{array}{l}\text { Broughton, D. B., R. W. Nenzil, J. M. Pharis and C. S. } \\
\text { Brearley: Chem. Eng. Progr, 66, } 70 \text { (1970). }\end{array}$ \\
\hline & 7) & Ching, C. B.: PhD Thesis, University of Aston, 1978. \\
\hline & 8) & Sanwa Denpun Process Bulletin, 1981. \\
\hline & 9) & $\begin{array}{l}\text { The Colonial Sugar Refining Company, Brit. Patent } 1083500 \text {, } \\
\text { Sept., } 1967 .\end{array}$ \\
\hline
\end{tabular}

\title{
SIMULATION OF NONISOTHERMAL PRESSURE SWING ADSORPTION
}

\author{
KAZUYUKI CHIHARA AND MOTOYUKI SUZUKI \\ Institute of Industrial Science, University of Tokyo, Tokyo 106
}

\begin{abstract}
Nonisothermal pressure swing adsorption is simulated by numerical calculation, by accounting for mass transfer as well as heat transfer in the column, where linear driving force for adsorption rate and linear isotherm were assumed. 40 cycles of PSA operation from start-up are iterated in the computer as a case study of air drying by activated alumina. Assuming that volumetric ratio of purge to feed is 2 , steady mode is observed after 30 cycles and almost constant distribution of amount adsorbed in the bed is found to be established. Condition for isothermal, nonisothermal or adiabatic assumption can be determined by this simulation in terms of column diameter. Bed length, cycle time and purge to feed ratio have significant effects on product concentration in the simulations. Further, optimizations are discussed as for the relation between column length and purge-to-feed ratio and as for cycle time in the case of air drying by silica gel.
\end{abstract}

\section{Introduction}

Pressure swing adsorption (PSA) processes are cyclic processes for the separation of gaseous mixtures. They were developed during the 1960's as a high-throughput replacement for adsorption processes employing thermal regeneration.

The principal steps involved in a pressure swing cycle are adsorption during pressurization, purified product removal during a high-pressure feed step, and desorption during blowdown to low pressure. A purge step may follow depressurization. A portion of the purified product is used as purge stream.

The higher throughput in pressure swing processes compared to temperature swing processes results

Received May 8, 1982. Correspondence concerning this article should be addressed to K. Chihara. from the more rapid response of a gas-solid system to pressure change than to temperature changes. The more rapid response permits shorter cycle times and hence greater throughput. Additional advantages claimed for pressure swing processes include low energy requirement and low capital investment costs.

Pressure swing processes are widely used industrially in air drying, hydrogen purification and production of low-purity oxygen from air. ${ }^{8)}$ These PSA separation processes utilize the difference between adsorption equilibria of components in a gas mixture.

From the theoretical viewpoint, few theoretical analyses of the operation have been reported for PSA separation in the literature. An equilibrium theory for single adsorbate was developed by Shendalman and Mitchell. ${ }^{7)}$ Weaver and Hamrin ${ }^{10)}$ and Chan et al. ${ }^{2)}$ reported equilibrium theories for competitive adsorp- 
tion. Further, mass transfer effects were considered by Mitchell and Shendalman ${ }^{6)}$ and Kawazoe and Kawai. ${ }^{4)}$ Turnock and Kadlec $^{9)}$ developed a theory which accounted for pressure variation. Also, Doshi et $a{ }^{37}{ }^{3)}$ discussed the optimization of PSA operation.

In the present work, non-equilibrium and nonisothermal pressure swing adsorption for the removal of one adsorbing impure component, such as air drying, is simulated numerically from start-up until steady cyclic mode is established. Non-equilibrium treatment of PSA is necessary for study of the purge to feed ratio, because the mass transfer rates have a significant effect on this ratio. Since PSA operation for air drying and air separation, etc., are inevitably non-isothermal, the heat transfer effect should be carefully accounted for in order that optimum operating conditions may be selected. After the simulation method is established, the effects of cycle time, adsorption rate constants, heat transfer parameters and column length on overall performance of PSA operations are examined by numerical experimentation. Optimizations based on this simulation are studied to minimize the total cost and to reduce the impurity in a product gas for the air dryer system.

\section{Non-isothermal Non-equilibrium Model}

One typical operation mode of the pressure swing adsorption cycle as shown in Fig. 1 consists of four distinct steps. In the first step high-pressure feed enters Bed 2 and product gas flows out. During this step a portion of the clean product passes through Bed 1 at a lower pressure to purge the accumulated adsorbate in Bed 1. In Step 2, Bed 1 is repressurized to feed pressure (repressurization) while the pressure in Bed 2 is reduced (blowdown). In Step 3, high-pressure feed flows through Bed 1 while a portion of the exiting product purges Bed 2 at a reduced pressure. The final portion of the sequence, Step 4, consists of blowdown of Bed 1 and repressurization of Bed 2.

For modeling the above operation, the following points are assumed.

1) One component of adsorbate is present in large excess of inert carrier gas.

2) Isotherm for adsorbing gas is linear and adsorption equilibrium coefficient depends on temperature.

3) Frictional pressure drop in a bed is negligible, although the pressure in each bed may vary with time.

4) Linear velocity of carrier gas is constant in Step 1 and Step 3.

5) Gas is assumed ideal and compressible.

6) One-dimensional formulation is made for a bed with no radial distribution of concentration and temperature.

7) Axial dispersion is neglected in mass balance
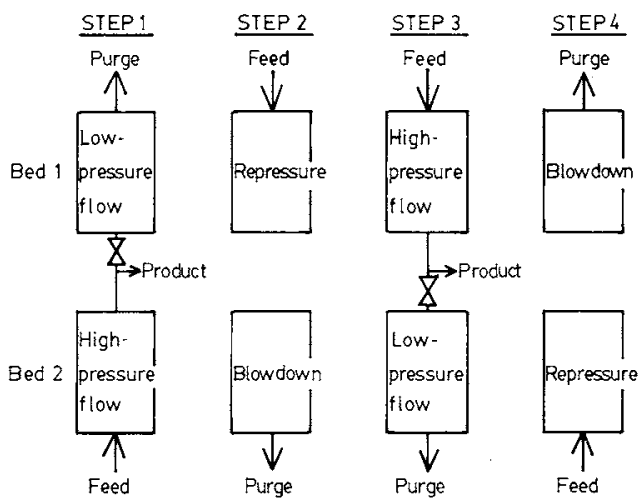

Fig. 1. Steps in a pressure swing adsorption.

expression.

8) Concentration distribution in the particle is neglected and linear driving force for the overall mass transfer between the solid and gas phase is taken for simplicity.

9) Heat transfer between bulk stream and vessel wall and thermal conduction in longitudinal direction in the bed are accounted for in heat balance expressions.

10) Thermal equilibrium is assumed between fluid and particies.

11) Temperature dependence of gas and solid properties and transport parameters are assumed negligible. Gas density and mass transfer parameter depend on pressure.

Based on these assumptions, basic equations are derived at high or low constant-pressure flow condition of Steps 1 and 3. Mass conservation of adsorbate in the bed leads to

$$
v \frac{\partial c}{\partial z}+\frac{\partial c}{\partial t}+\frac{\gamma}{\varepsilon} \frac{\partial q}{\partial t}=0
$$

Overall mass transfer between the solid and gas phase (i.e. adsorption rate) is

$$
\gamma \frac{\partial q}{\partial t}=K_{s} a_{v}\left(q^{*}-q\right)
$$

Adsorption equilibrium is

$$
q^{*}=k \cdot c
$$

Temperature dependency of adsorption coefficient is

$$
\ln \frac{k}{k_{0}}=\frac{Q}{R}\left(\frac{1}{T}-\frac{1}{T_{0}}\right)
$$

Heat balance in the bed is

$$
\begin{aligned}
& \frac{k_{e z}}{\varepsilon} \frac{\partial^{2} T}{\partial z^{2}}-v \rho_{\mathrm{g}} C_{p g} \frac{\partial T}{\partial z}+\frac{2 h_{0}}{\varepsilon r}\left(T_{0}-T\right) \\
& -\left(\rho_{\mathrm{g}} C_{p g}+\frac{\gamma}{\varepsilon} C_{p s}\right) \frac{\partial T}{\partial t}+\frac{\gamma}{\varepsilon} Q \frac{\partial q}{\partial t}=0
\end{aligned}
$$

where 


$$
\begin{array}{ll}
v=v_{H} & \text { for high-pressure flow } \\
v=-v_{L}=-\alpha v_{H} & \text { for purge flow }
\end{array}
$$

and $\rho_{g}$ changes with pressure.

Boundary conditions for high-pressure flow are

$$
c=c_{0}, \quad q=q_{0}^{*}, \quad T=T_{0} \quad \text { at } \quad z=0
$$

and for low-pressure flow

$$
\begin{gathered}
c(L, t)=\left(P_{L} / P_{H}\right) c\left(L, t-t_{1}\right), \\
T(L, t)=T_{0} \quad \text { at } z=L
\end{gathered}
$$

The behavior of the system during a rapid pressure change is very complicated since flow into or out of the porous adsorbent particles takes place. We do not attempt to take into account this part of the process in detail. The pressure change is assumed to be so rapid that no exchange occurs during this period between the solid and gas as assumed by Mitchell and Shendalman. ${ }^{6)}$ The solid composition is assumed to be frozen at the end of Steps 1 and 3 and remains constant throughout Steps 2 and 4. For a blowdown, the gas-phase concentration profile at the end of highpressure flow is averaged and reduced in proportion to the ratio of high and low operation pressures. For a repressurization, the adsorbate concentration in gas phase is not changed, while the total pressure is increased.

Basic equations (1) to (7) are converted to nondimensional form as follows.

$$
\begin{aligned}
& \frac{\partial \bar{c}}{\partial \bar{t}}+\tau_{\mathrm{a}} \frac{\partial \bar{c}}{\partial \bar{z}}+\tau_{\mathrm{b}} \frac{\partial \bar{q}}{\partial \bar{t}}=0 \\
& \frac{\partial \bar{q}}{\partial \bar{t}}=\tau_{\mathrm{f}}\left(\bar{q}^{*}-\bar{q}\right) \\
& \bar{q}^{*}=K \bar{c} \\
& K=\exp \left\{-\frac{Q}{R T_{0}} \cdot \frac{\bar{T}}{(\bar{T}+1)}\right\} \\
& \frac{\partial \bar{T}}{\partial \bar{t}}+\tau_{\mathrm{H}} \frac{\partial \bar{T}}{\partial \bar{z}}-\tau_{\mathrm{L}} \frac{\partial^{2} \bar{T}}{\partial \bar{z}^{2}}+\tau_{\mathrm{W}} \bar{T}-\beta \frac{\partial \bar{q}}{\partial \bar{t}}=0
\end{aligned}
$$

with B.C for high-pressure flow

$$
\bar{c}=\bar{q}=1, \quad \bar{T}=0 \quad \text { at } \quad \bar{z}=0
$$

and for low-pressure flow

$$
\begin{gathered}
\vec{c}(1, \bar{t})=\left(P_{L} / P_{H}\right) \cdot \bar{c}\left(1, \bar{t}-\bar{t}_{1}\right), \\
\bar{T}(1, \bar{t})=0 \quad \text { at } \quad \bar{z}=1
\end{gathered}
$$

where the nondimensional parameters are

$$
\tau_{\mathrm{a}}=\frac{t_{0}}{(L / v)}=\frac{(\text { time for bed saturation })}{(\text { retention time of carrier gas })}
$$

(amount adsorbed per unit bed

$$
\tau_{\mathrm{b}}=\frac{\gamma q_{0}^{*}}{\varepsilon c_{0}}=\frac{\text { volume at equilibrium to } \left.c_{0}\right)}{\begin{array}{l}
\text { (adsorbate concentration in gas phase } \\
\text { per unit bed volume at inlet conc. } \left.c_{0}\right)
\end{array}}\left(9^{\prime}\right)
$$

$$
\tau_{\mathrm{f}}=\frac{t_{0}}{\left(\gamma / K_{\mathrm{s}} a_{v}\right)}=\frac{(\text { time for bed saturation) }}{\left(\begin{array}{c}
\text { (time constant for adsorption } \\
\text { to the adsorbent) }
\end{array}\right.}
$$

$$
\begin{aligned}
\tau_{\mathrm{H}} & =\frac{\left(\varepsilon v \rho_{\mathrm{g}} C_{p g} t_{0}\right)}{L\left(\varepsilon \rho_{\mathrm{g}} C_{p g}+\gamma C_{p s}\right)} \\
& =\frac{\text { (heat capacity of total gas flowed in } \left.t_{0}\right)}{\text { (heat capacity of the bed) }}
\end{aligned}
$$

$$
\begin{aligned}
\tau_{\mathrm{L}} & =\frac{t_{0}}{\left(\varepsilon \rho_{\mathrm{g}} C_{p g}+\gamma C_{p s}\right) L^{2} / k_{e z}} \\
& =\frac{\text { (time for bed saturation) }}{\left(\begin{array}{c}
\text { (time constant for effective longitudinal } \\
\text { thermal conduction) }
\end{array}\right.}
\end{aligned}
$$

$$
\begin{aligned}
\tau_{\mathrm{W}} & =\frac{t_{0}}{\left\{\left(\varepsilon \rho_{\mathrm{g}} C_{p g}+\gamma C_{p s}\right) r / 2 h_{0}\right\}} \\
& =\frac{\text { (time for bed saturation) }}{\text { (time constant for heat transfer through wall) }}
\end{aligned}
$$

$$
\begin{aligned}
& \beta= \frac{\gamma Q q_{0}^{*}}{\left(\varepsilon \rho_{\mathrm{g}} C_{p g}+\gamma C_{p s}\right) T_{0}} \\
&=\frac{\begin{array}{l}
\text { (total heat generated by saturation } \\
\text { (total heat sustained at } T_{0}
\end{array}}{\text { per unit volume in the bed) }}
\end{aligned}
$$

with characteristic time, that is, saturation time, as

$$
t_{0}=L \gamma q_{0}^{*} / \varepsilon v_{H} c_{0}
$$

Initial transient period from evacuated condition up to steady operation are simulated, using the Crank-Nicolson implicit method. In the following case study, $\Delta \bar{t}$ is $1 / 50,000$ and $\Delta \bar{z}$ is $1 / 40$.

\section{Simulation for Standard Case}

Air drying using activated alumina is simulated here as a case study of non-isothermal pressure swing adsorption by the method described in the previous section. The necessary parameters for numerical computations are tabulated in Table 1. Adsorption equilibrium is assumed to be linear for activated alumina. Pore diffusion controlling is reported by Carter and Barrett. ${ }^{1)}$ Heat-transfer effects are accounted for, using effective thermal conductivity in axial direction and overall heat transfer coefficient through the wall.

The dimensionless parameters for this standard case are shown in Table 2 (case 1).

Simulation results are shown in Figs. 2(a) to (c), Figs. 3(a) to (f) and Figs. 4-1(a) to (c). Gas-phase concentration (Fig. 2(a)), amount adsorbed (Fig. 2(b)) and temperature (Fig. 2(c)) at 5 points in the bed $(\bar{z}=0,0.25,0.5,0.75,1)$ change with time in the 
Table 1. Physical parameters for computation of case 1

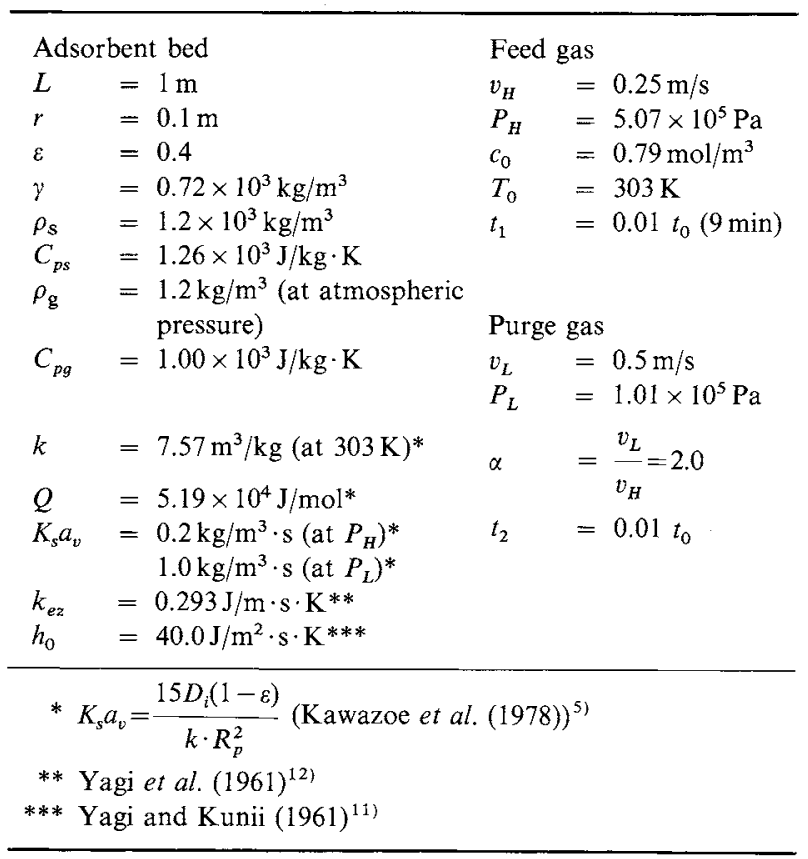

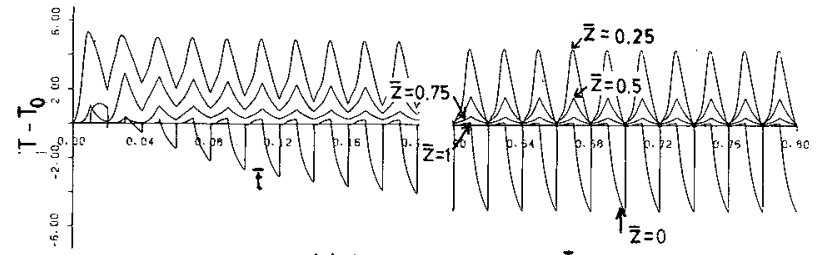

(c) temperature vs. T

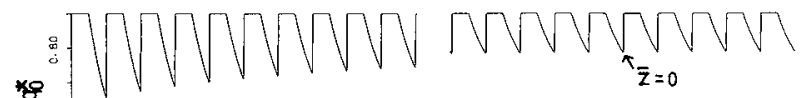

(b) amount adsorbed vs. $\overline{\mathrm{t}}$
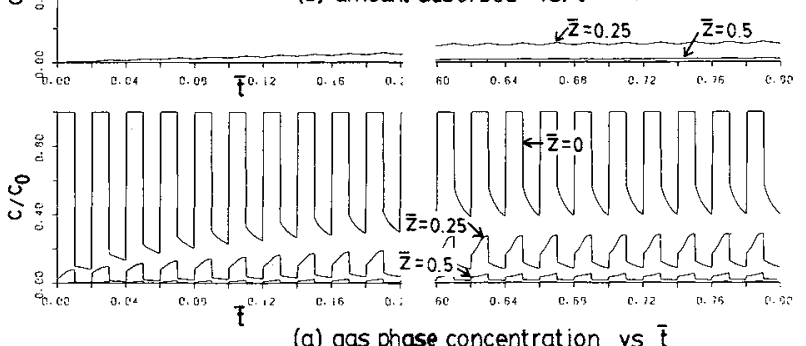

(a) gas phase concentration vs, $\overline{\mathrm{t}}$

Fig. 2. Transition from start-up to steady operation (case 1, non-isothermal).

Table 2. Dimensionless parameters and $t_{0}$ for computation runs

\begin{tabular}{|c|c|c|c|c|c|c|c|}
\hline & & $\begin{array}{c}\text { Case } 1 \\
\text { (non-isothermal) }\end{array}$ & $\begin{array}{c}\text { Case } 2 \\
\text { (isothermal) }\end{array}$ & $\begin{array}{c}\text { Case } 3 \\
\text { (adiabatic) }\end{array}$ & $\begin{array}{c}\text { Case } 4 \\
L=0.5 \mathrm{~m}\end{array}$ & $\begin{array}{c}\text { Case } 5 \\
t_{1}=0.005 t_{0}\end{array}$ & $\begin{array}{l}\text { Case } 6 \\
\alpha=1.0\end{array}$ \\
\hline \multirow[t]{2}{*}{$\tau_{\mathbf{a}}$} & at adsorption & 13700 & 13700 & 13700 & 13700 & 13700 & 13700 \\
\hline & at desorption & 27400 & 27400 & 27400 & 27400 & 27400 & 13700 \\
\hline$\tau_{\mathrm{b}}$ & & 13700 & 13700 & 13700 & 13700 & 13700 & $\overline{13700}$ \\
\hline \multirow[t]{2}{*}{$\tau_{\mathrm{f}}$} & at adsorption & 15.2 & 15.2 & 15.2 & 7.61 & 15.2 & 15.2 \\
\hline & at desorption & 76.1 & 76.1 & 76.1 & 38.0 & 76.1 & 76.1 \\
\hline \multirow[t]{2}{*}{$\tau_{\mathrm{H}}$} & at adsorption & 36.4 & 36.4 & 36.4 & 36.4 & 36.4 & 36.4 \\
\hline & at desorption & 14.6 & 14.6 & 14.6 & 14.6 & 14.6 & 7.30 \\
\hline \multicolumn{2}{|l|}{$\tau_{\mathbf{L}}$} & 0.0177 & 0.0177 & 0.0177 & $\underline{0.0354}$ & 0.0177 & $\overline{0.0177}$ \\
\hline \multicolumn{2}{|l|}{$\tau_{w}$} & 48.5 & 48.5 & 0.0 & 24.2 & 48.5 & 48.5 \\
\hline \multicolumn{2}{|l|}{$\beta$} & 0.818 & $\underline{0.0}$ & $\overline{0.818}$ & 0.818 & 0.818 & 0.818 \\
\hline \multicolumn{2}{|c|}{$t_{1}$ and $t_{2}$} & $0.01(9 \mathrm{~min})$ & $\overline{0.01}$ & 0.01 & $\frac{0.01}{(4.5 \mathrm{~min})}$ & 0.005 & 0.01 \\
\hline \multicolumn{2}{|l|}{$t_{0}$} & $54800 \mathrm{sec}(15 \mathrm{hr})$ & 54800 & 54800 & $\underline{27400}$ & 54800 & 54800 \\
\hline
\end{tabular}

initial transient cyclic operation. This transient cyclic behavior approaches steady operation after 30 cycles in this case. Profiles of $\bar{c}, \bar{q}$ and $T-T_{0}$ in the bed at the end of the adsorption step and purge step for every five cycles are given in Figs. 4-1(a) to (c). Fully developed profiles (i.e. steady cyclic mode) are asymptotically formed in the bed for each variable, $\bar{c}, \bar{q}$ and $T-T_{0}$. The final outlet concentration at the end of high-pressure flow in the 40th cycle are almost $1.9 \times 10^{-5} \mathrm{~kg} / \mathrm{m}^{3}$ at $P_{H}$ in this case, corresponding to a dew point of $-55^{\circ} \mathrm{C}$ (Table 3 ).

Figures 3(a) to (f) show profiles of $\bar{c}, \bar{q}$ and $T-T_{0}$ versus $\bar{t}$ or $\bar{z}$, respectively, for the 40 th cycle. Gasphase concentration (Fig. 3(a)), amount adsorbed (Fig. 3(b)) and temperature (Fig. 3(c)) at 5 points in the bed $(\bar{z}=0,0.25,0.5,0.75,1)$ vary in the course of Steps 1, 2, 3 and 4 at the 40 th cycle. These profiles are repeated in a steady manner. In Fig. 3(a), concentrations at the instantaneous blowdown are not plotted because of the memory capacity of the computer. Hence plotted results at blowdown seem not to obey the model mentioned in this work, although the computation was done according strictly by the model. First points plotted were at $\bar{t}=0.0104$ after blowdown. The final distributions of gas-phase concentration (Fig. 3(d)), amount adsorbed (Fig. 3(e)) and temperature (Fig. 3(f)) at both low- and highpressure operation are shown. The adsorbent near $\bar{z}=0$ is always saturated with water and the portion near $\bar{z}=1$ is dry enough to supply the dried air in steady operation according to Fig. 3(e). This distribution of amount adsorbed is maintained throughout steady cyclic operation. The difference between the two curves in Fig. 3(e) is the effective adsorption 

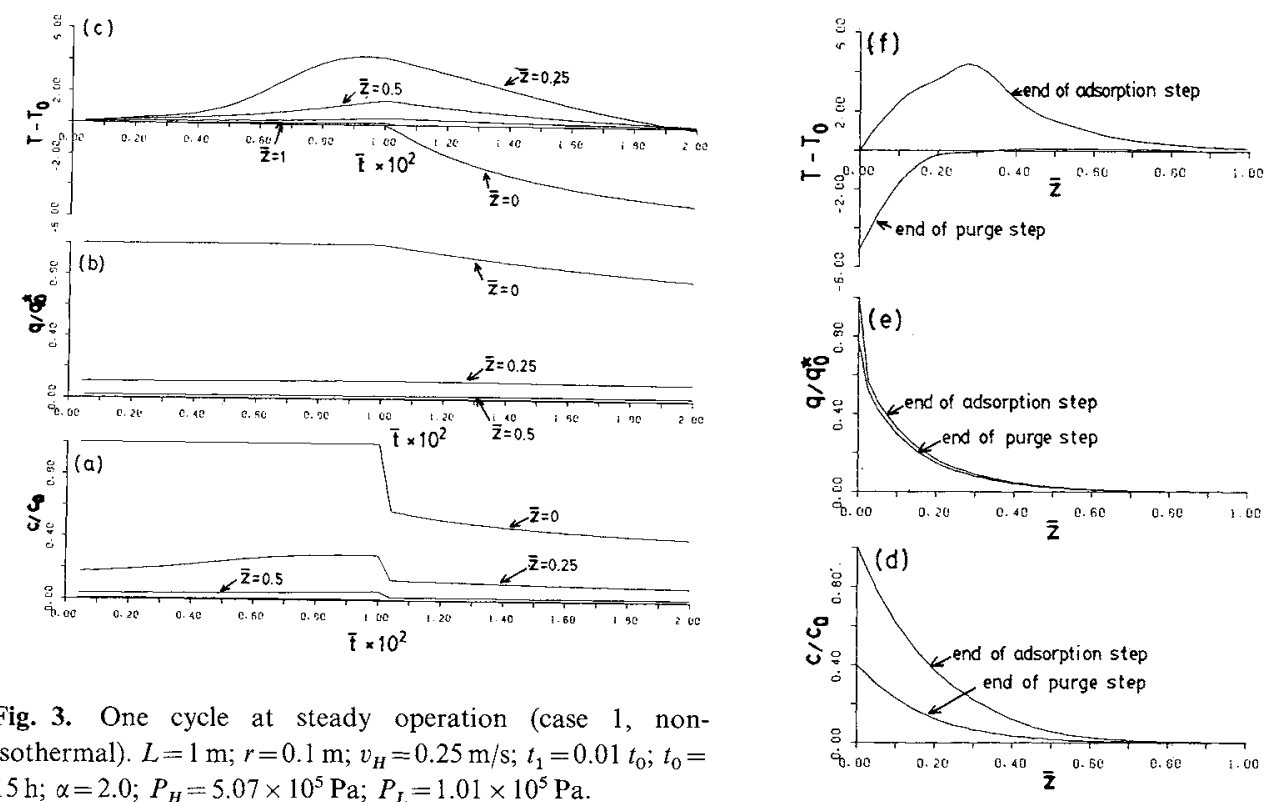

Fig. 3. One cycle at steady operation (case 1, nonisothermal). $L=1 \mathrm{~m} ; r=0.1 \mathrm{~m} ; v_{H}=0.25 \mathrm{~m} / \mathrm{s} ; t_{1}=0.01 t_{0} ; t_{0}=$ $15 \mathrm{~h} ; \alpha=2.0 ; P_{H}=5.07 \times 10^{5} \mathrm{~Pa} ; P_{L}=1.01 \times 10^{5} \mathrm{~Pa}$.

capacity in one cycle, which is almost $1 / 100$ of the total capacity of the adsorbents packed in the bed since $t_{1}$ is $0.01 t_{0}$ in this case. It seems, however, that the total bed length is used effectively to produce dried air, because the total bed is needed to keep the distribution of amount adsorbed. Further, the heat capacity of the total packed bed is found to be working as an accumulator for the heat generated by adsorption. The heat accumulated is utilized in the desorption step. The heat released through the wall could be partly recovered in the desorption cycle, while the heat escaping with the outlet gas cannot be recovered. Hence it is important to maintain the temperature at ambient condition near the outlet in the adsorption cycle from the viewpoint of energy saving and/or good PSA performances.

\section{Discussion}

\subsection{Effect of heat transfer through the wall}

Necessity of isothermal or adiabatic analysis of packed bed adsorption depends mainly on the magnitude of amount adsorbed, isosteric heat of adsorption, overall heat transfer coefficient and column radius. It is useful to set the criteria for judging the isothermal, non-isothermal or adiabatic condition. Here we tried to find the range of radius corresponding to each isothermal, non-isothermal or adiabatic condition for the standard condition given in Table 1 except radius $r$. By assuming $Q=0$, profiles of $\bar{c}$ and $\bar{q}$ were obtained as an isothermal case in Figs. 4-2(a) and (b) (case 2). The assumption is equivalent to assuming $\tau_{\mathrm{W}}=\infty$.

Profiles for the adiabatic case are shown in Figs. 4-3(a), (b) and (c) (case 3). The parameters used for computation are summarized in Table 2. Almost- steady modes are established after 30 cycles in all three conditions. As a result, the final outlet concentrations of the 40th adsorption step for different $\tau_{\mathrm{W}}$ can be compared by fixing the other parameters (Table 3).

This outlet concentration at steady operation rises about four times from isothermal condition $\left(\tau_{\mathrm{W}}=\infty\right)$ to adiabatic condition $\left(\tau_{\mathrm{w}}=0\right)$. The plot of the concentration in product stream of the 40th adsorption step versus $\tau_{\mathrm{W}}$ (Fig. 5) shows that when $r$ is smaller than $0.05 \mathrm{~m}$, isothermal treatment is possible, and when $r$ is larger than $0.9 \mathrm{~m}$ adiabatic assumption is reasonable in this case within $10 \%$ error, while more general non-isothermal treatment is necessary when $r$ is between 0.05 and $0.9 \mathrm{~m}$.

\subsection{Effect of parameters}

1) Bed length Simulated results with the design parameter $L$ changed to $1 / 2$ of the standard case are given in Figs. 4-4(a) to (c), assuming other parameters to be the same as in the standard case (case 1) (Table 2). The final outlet concentration in the 40th adsorption step is almost 20 times bigger than the standard case (case 1), as shown in Table 3. The practical indicator, i.e. dew point, is also given in Table 3. The dew point of the final product in 40th cycle is found to be very high in this case. Therefore, bed length $L$ is one of the important design parameters.

2) Cycle time Cycle time of case 5 is taken as half of that for the standard case (case 1), while other parameters are the same (see Table 2 and Fig. 4-5). The final product concentration at 40 th cycle is $1 / 3$ lower than that of the standard case (Table 3). Hence cycle time as one of the operation parameters could be an adjustable parameter, to be determined from the product concentration desired.

3) Purge-to-feed ratio Case 6 corresponds to 

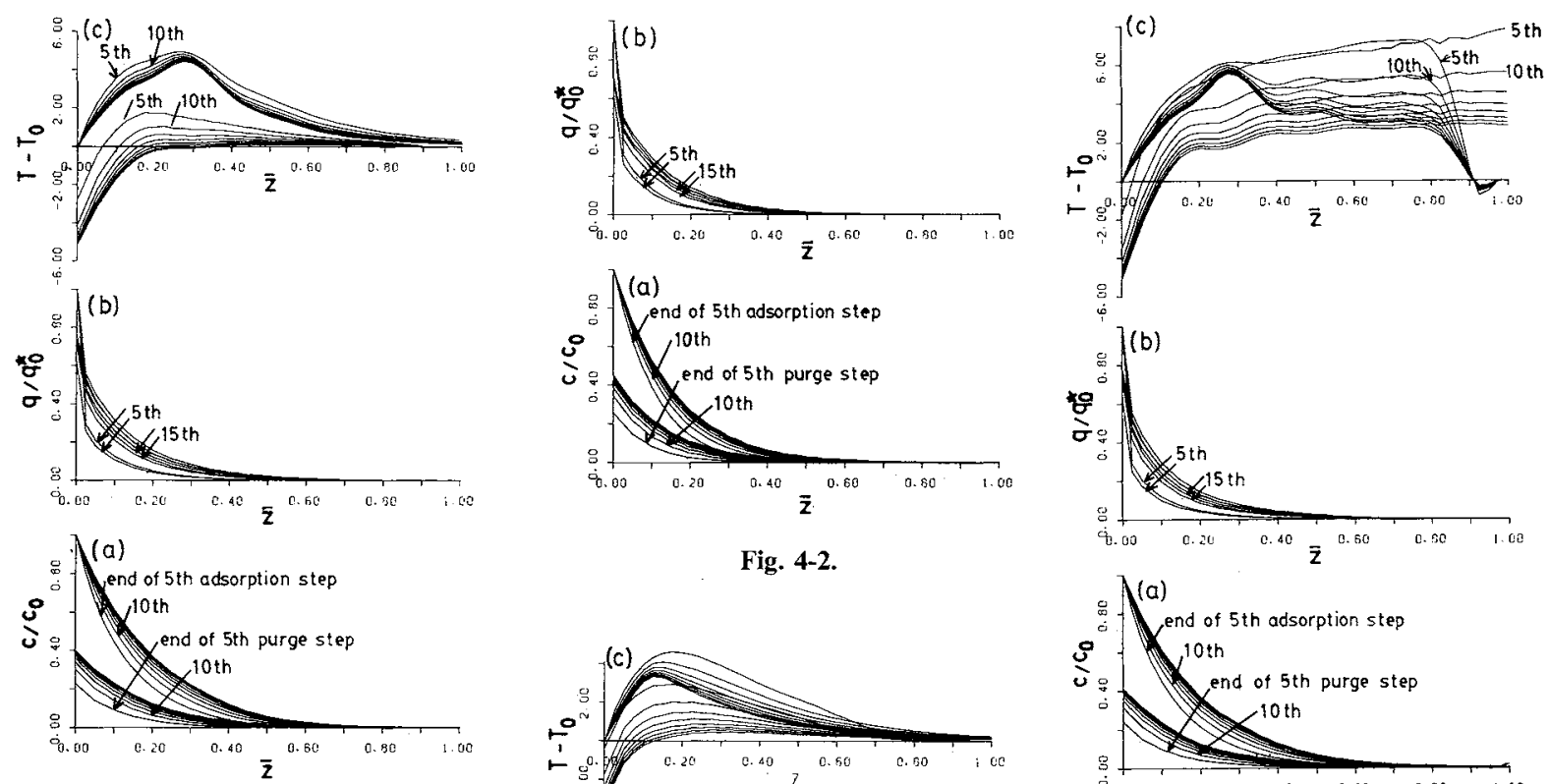

Fig. 4-2.

Fig. 4-1.
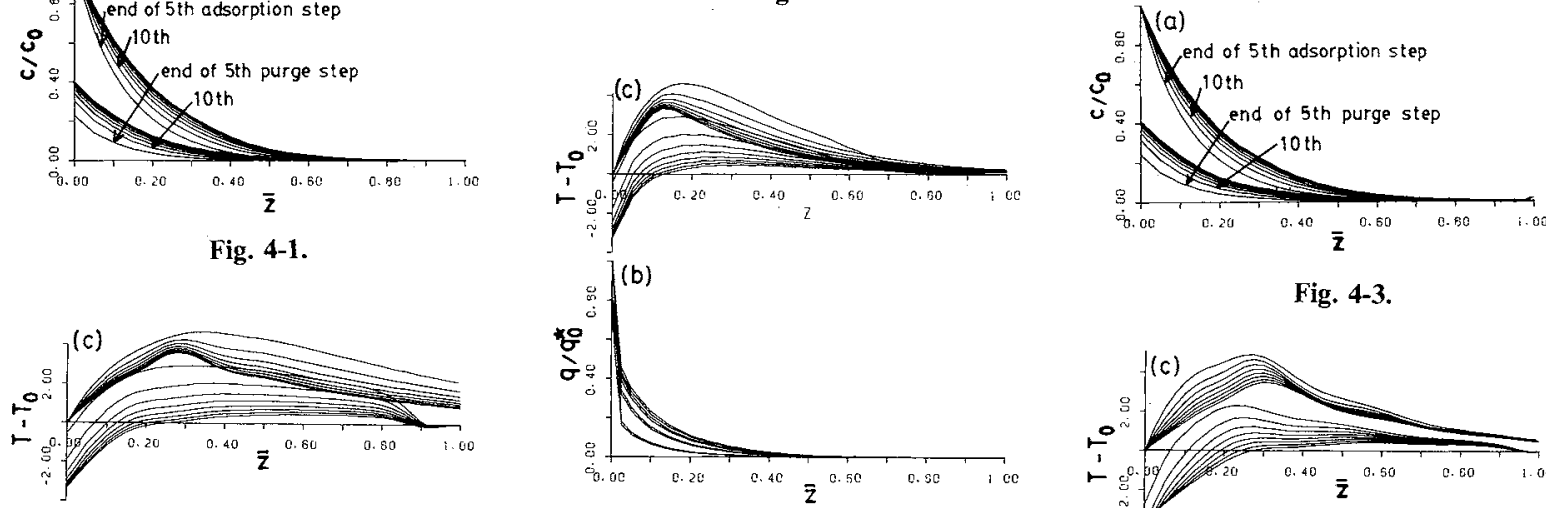

Fig. 4-3.
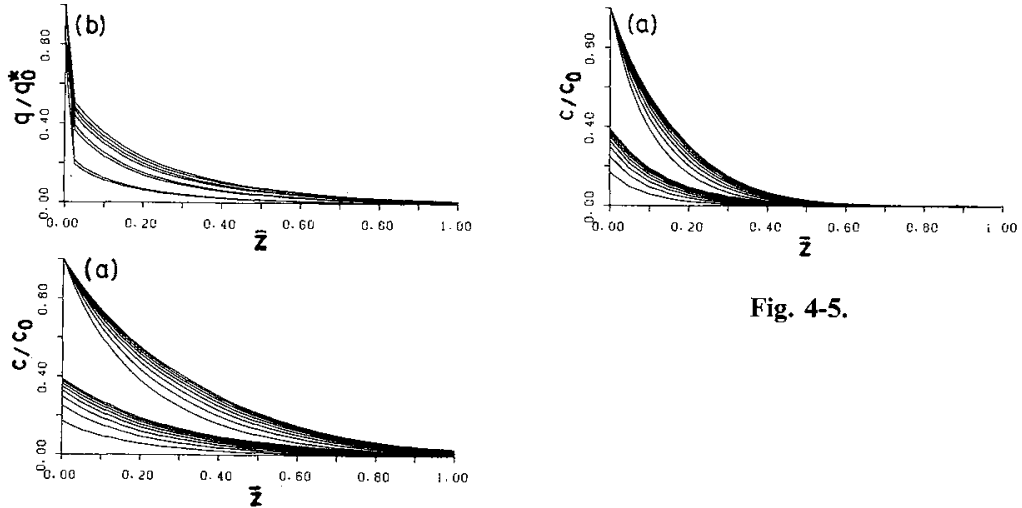

Fig. 4-5.

Fig. 4-4. Fig. 4. Comparison of $\bar{c}, \bar{q}$ and $T-T_{0}$ profiles for cases 1 to 6. 4-1, case 1 (non-isothermal); 4-2, case 2 (isothermal); 4-3, case 3 (adiabatic); 4-4, case $4 ; 4-5$, case $5 ; 4-6$, case 6 . Conditions are the same as that of Fig. 3 except for $Q=$ $0.0 \mathrm{~J} / \mathrm{mol}$ in case $2, h_{0}=0.0 \mathrm{~J} / \mathrm{m}^{2} \cdot \mathrm{s} \cdot \mathrm{K}$ in case $3, L=0.5 \mathrm{~m}$ in case $4, t_{1}=0.005 t_{0}$ in case 5 and $\alpha=1.0$ in case 6 .

Table 3. Outlet concentration at end of 40 th adsorption step

\begin{tabular}{lcc}
\hline & $c_{\text {oud }} / c_{0}$ & Dew point $\left[{ }^{\circ} \mathrm{C}\right]$ \\
\hline Case 1 (non-isotherma1) & $0.134 \times 10^{-2}$ & -55 \\
Case 2 (isothermal) & $0.750 \times 10^{-3}$ & -60 \\
Case 3 (adiabatic) & $0.338 \times 10^{-2}$ & -48 \\
Case 4 $(L=0.5 \mathrm{~m})$ & $0.318 \times 10^{-1}$ & -27 \\
Case 5 $\left(t_{1}=0.005 t_{0}\right)$ & $0.418 \times 10^{-3}$ & -65 \\
Case 6 $(\alpha=1.0)$ & $0.575 \times 10^{-2}$ & -43 \\
\hline
\end{tabular}

Skarstrom's $1: 1$ volume theory. ${ }^{8)}$ Here, volumetric purge-to-feed ratio is taken to be unity (Table 2). The results are in Fig. 4-6 and Table 3. Evidently the steady mode is not achieved in the computation up to 40 th cycel in this case. More calculation is necessary to judge whether steady operation exists or not. At least, the final outlet concentration of the 40th adsorption step is worse than that of case 1. Even though steady operation might exist, the product concentration could not be best in this condition of $1: 1$ purge-to-feed ratio.

\subsection{Example of optimization}

Optimization of column design and operation conditions are discussed in the following sections, using the simulation developed in this work. Air drying by silica gel is substantially assumed here. 


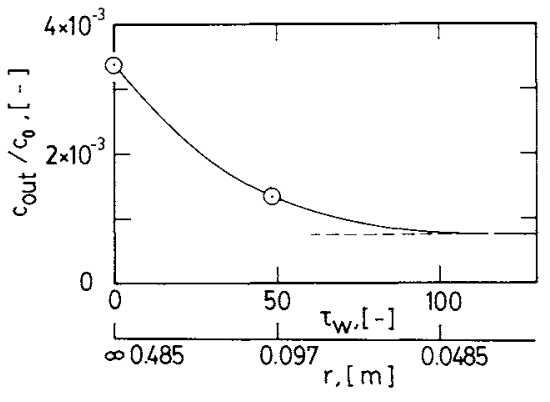

Fig. 5. Example of dependency of final outlet concentration in adsorption step on heat transfer parameter through the wall.

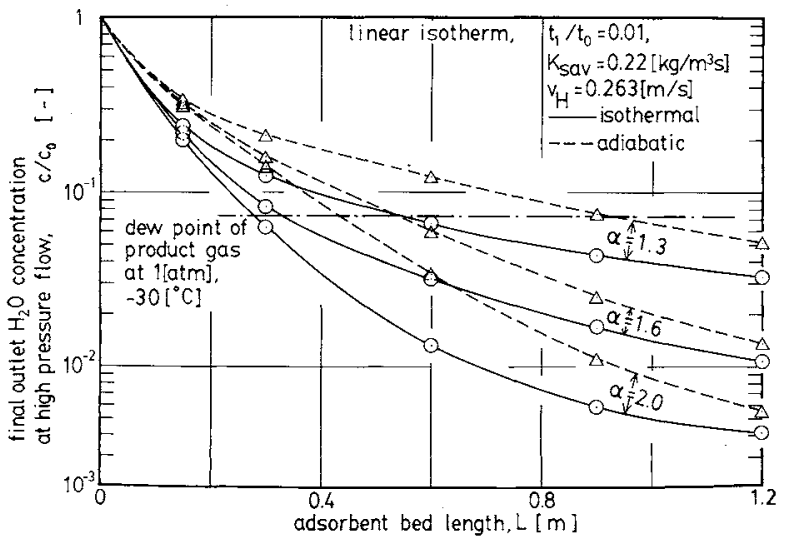

Fig. 6. Dependence of product concentration on bed length and volumetric purge-to-feed ratio

1) Optimization for the relation between the volumetric purge to feed ratio, $\alpha$ and column length, $L$ The respective effects of bed length, $L$, and volumetric purge-to-feed ratio, $\alpha$, on product concentration was briefly discussed above. Here the final outlet concentrations (80th cycle) are calculated for different conditions of $L$ and $\alpha$ in both the isothermal and adiabatic cases, fixing the throughput ratio, $t_{1} / t_{0}$ (Fig. 6). Parameters for computations are in Table 4(a). Surface diffusion is assumed as an intraparticle diffusion so that $K_{s} a_{v}$ does not change even though operation pressure varies. Figure 6 shows reasonably that final outlet concentration, $c / c_{0}$, decreases as bed length, $L$, increases and as volumetric purge to feed ratio, $\alpha$, increases. Product concentrations for the isothermal case are lower than the corresponding concentration for the adiabatic case.

The intersection of each solid line with the chain line gives a combination of $L$ and $\alpha$ to get the product gas, dew point of which is $-30^{\circ} \mathrm{C}$ at $1 \mathrm{~atm}$. This choice of $-30^{\circ} \mathrm{C}$ is just an example. These combinations are plotted as $\alpha$ versus $L$ in Fig. 7. The solid line for the isothermal case means that $\alpha$ could be reduced by increasing $L$, that is, maintenance cost is smaller for the longer column to get a desired dew point. On the other hand, the longer column has a higher construction cost. Therefore, one optimization for the choice of $\alpha$ and $L$ combination is possible if the relations between $\alpha$ and running cost and between $L$
Table 4. Parameters for optimization

(a)

$$
\begin{array}{lll}
L & =\text { variable }[\mathrm{m}] \\
k & =15.0 \mathrm{~m}^{3} / \mathrm{kg} \\
K_{s} a_{v} & =0.22 \mathrm{~kg} / \mathrm{m}^{3} \cdot \mathrm{s} \quad \text { (at } P_{H} \text { and } P_{L} \text { ) } \\
v_{H} & =0.263 \mathrm{~m} / \mathrm{s} \\
c_{0} & =1.28 \mathrm{~mol} / \mathrm{m}^{3} \\
T_{0} & =298^{\circ} \mathrm{C} \\
t_{1} / t_{0} & =0.01 \\
\alpha & =\text { variable } \\
t_{2} / t_{0} & =0.01
\end{array}
$$

Other parameters are the same as in Table 1.

(b)

$$
\begin{array}{ll}
L & =0.3 \mathrm{~m} \\
K_{\mathrm{s}} a_{v} & =0.66 \mathrm{~kg} / \mathrm{m}^{3} \cdot \mathrm{s} \\
t_{1} / t_{0} & =\text { variable }[-] \\
\text { Other parameters are the same as in (a). } & \\
\text { In the case of Freundlich isotherm } \\
\begin{array}{ll}
\bar{q}^{*} & =\bar{c}^{1 / 1.6} \\
q_{0}^{*} & =19.2 \mathrm{~mol} / \mathrm{kg} \\
K_{s} a_{v} & =0.4 \mathrm{~kg} / \mathrm{m}^{3} \cdot \mathrm{s}
\end{array}
\end{array}
$$

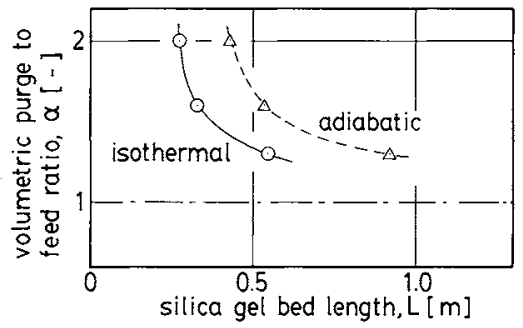

Fig. 7. Combination of bed length and volumetric purgeto-feed ratio for getting a product dew point of $-30^{\circ} \mathrm{C}$.

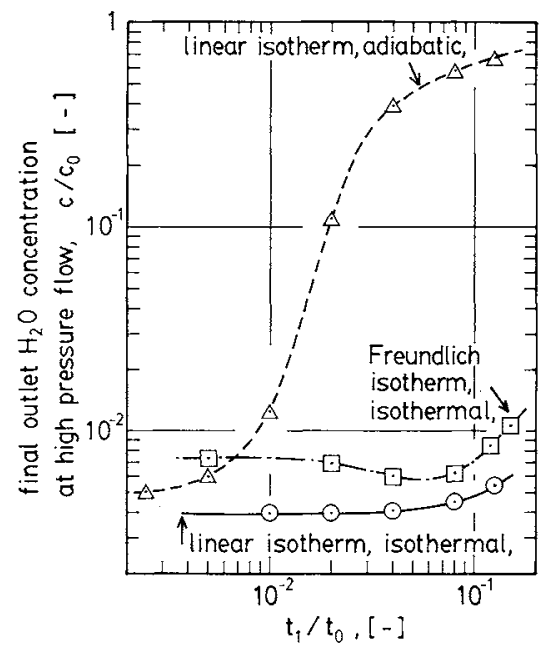

Fig. 8. Dependence of product concentration on throughput ratio.

and construction cost are both given. This procedure is applicable for the non-isothermal and adiabatic cases. An example of $\alpha$ and $L$ relation for the adiabatic case to get $-30^{\circ} \mathrm{C}$ dew point is also shown in Fig. 7.

2) Choice of throughput ratio, $t_{1} / t_{0}$ Nondimensional adsorption cycle time, $t_{1} / t_{0}$, (throughput ratio) is one of the factors which determine product concentration. Figure 8 shows the effects of throughput 
ratio on final outlet $\mathrm{H}_{2} \mathrm{O}$ concentration for various cases denoted. ( 80 to 320 cycles are simulated to reach almost the same total operation time. Parameters are in Table $\mathbf{4}(\mathbf{b})$.) When $t_{1} / t_{0}<0.1$, almost no change of outlet concentration is observed for either linear or Freundlich isotherm in isothermal operation. The increase of $c / c_{0}$ at $t_{1} / t_{0}>0.1$ is the normal breakthrough of concentration. In the adiabatic case with linear isotherm, outlet concentration increases at $t_{1} / t_{0}>0.01$. This deterioration is attributed to the temperature rise of the bed up to the outlet. This tendency is observed also in the brief discussion above for the non-isothermal case with activated alumina. Therefore, it is necessary to set the throughput ratio, $t_{1} / t_{0}$ small enough to prevent thermal breakthrough.

\section{Summary}

Simulation of non-isothermal pressure swing adsorption was carried out. Non-isothermal conditions are common in air drying and bulk separation of air. The model consists of four steps, i.e. instantaneous repressurization, adsorption at high pressure, instantaneous blowdown and purge by part of the product at low pressure. Mass transfer and heat transfer in the bed and overall adsorption rate are accounted for by assuming a linear adsorption isotherm.

A case study for air drying by activated alumina was made. Iterated computation was tried for the initial 40 cycles of PSA operation. Six cases were chosen, i.e. standard case (non-isothermal), isothermal case, adiabatic case, and three other cases in each of which one of the three parameters bed length, cycle time or purge-to-feed ratio was changed from the standard case.

In five cases with volumetric purge-to-feed ratio $(\alpha)=2$, steady operation was observed after 30 cycles. A steady distribution of amount adsorbed was gradually formed in the axial direction. Further, the significance of bed length as a design parameter and that of cycle time as an operation parameter were recognized by simulation with the changed parameter. Existence of steady mode for $\alpha=1$ was not confirmed.

Further, two optimizations were tried, using this simulation method. One was for selection of the best relation between volumetric purge-to-feed ratio and bed length, supposing the desired product concentration, to attain the minimum total cost. The other was the choice of throughput ratio, i.e. cycle time, to keep the outlet concentration at low level.

$\begin{array}{llr}\text { Nomenclature } & \\ C_{p g} & =\text { heat capacity of gas } & {[\mathrm{J} / \mathrm{kg} \cdot \mathrm{K}]} \\ C_{p s} & =\text { heat capacity of adsorbent } & {[\mathrm{J} / \mathrm{kg} \cdot \mathrm{K}]} \\ c & =\text { adsorbate concentration in gas phase } & {\left[\mathrm{mol} / \mathrm{m}^{3}\right]} \\ \bar{c} & =c / c_{0} & {[-]}\end{array}$

\begin{tabular}{|c|c|c|}
\hline$c_{0}$ & $=$ adsorbate concentration in feed gas & {$\left[\mathrm{mol} / \mathrm{m}^{3}\right]$} \\
\hline$D_{i}$ & $=$ effective intraparticle diffusivity & {$\left[\mathrm{m}^{2} / \mathrm{s}\right]$} \\
\hline$h_{0}$ & $\begin{aligned}= & \text { overall heat transfer coefficient } \\
& \text { through the wall }\end{aligned}$ & {$\left[\mathrm{J} / \mathrm{m}^{2} \cdot \mathrm{s} \cdot \mathrm{K}\right]$} \\
\hline$K$ & $=k / k_{0}$ & {$[-]$} \\
\hline$K_{\mathrm{s}} a_{v}$ & $=$ overall mass transfer coefficient & {$\left[\mathrm{kg} / \mathrm{m}^{3} \cdot \mathrm{s}\right]$} \\
\hline$k$ & $=$ adsorption equilibrium constant & {$\left[\mathrm{m}^{3} / \mathrm{kg}\right]$} \\
\hline$k_{0}$ & $=k$ at ambient temperature, $T_{0}$ & {$\left[\mathrm{~m}^{3} / \mathrm{kg}\right]$} \\
\hline$k_{e z}$ & $\begin{aligned}= & \text { effective thermal conductivity in } \\
& \text { axial direction }\end{aligned}$ & {$[\mathrm{J} / \mathrm{m} \cdot \mathrm{s} \cdot \mathrm{K}]$} \\
\hline$L$ & $=$ adsorbent bed length & [m] \\
\hline$P_{H}$ & $=$ pressure in adsorbent bed in adsorptio & on step $[\mathrm{Pa}]$ \\
\hline$P_{L}$ & $=$ pressure in adsorbent bed in purge step & {$[\mathrm{Pa}]$} \\
\hline$Q$ & $=$ isosteric heat of adsorption & {$[\mathrm{J} / \mathrm{mol}]$} \\
\hline$q$ & $=$ amount adsorbed & {$[\mathrm{mol} / \mathrm{g}]$} \\
\hline $\bar{q}$ & $=q / q_{0}^{*}$ & {$[-]$} \\
\hline$q^{*}$ & $=k \cdot c$ & {$[\mathrm{~mol} / \mathrm{kg}]$} \\
\hline $\bar{q}^{*}$ & $=q^{*} / q_{0}^{*}$ & {$[-]$} \\
\hline$q_{0}^{*}$ & $=k_{0} \cdot c_{0}$ & {$[\mathrm{~mol} / \mathrm{kg}]$} \\
\hline$R$ & $=$ gas constant & {$[\mathrm{J} / \mathrm{mol} \cdot \mathrm{K}]$} \\
\hline$R_{p}$ & $=$ adsorbent particle radius & [m] \\
\hline$r$ & $=$ radius of adsorbent bed & [m] \\
\hline$T$ & $=$ temperature in the bed & {$[\mathrm{K}]$} \\
\hline $\bar{T}$ & $=\left(T-T_{0}\right) / T_{0}$ & {$[-]$} \\
\hline$T_{0}$ & $=$ ambient temperature & {$[\mathrm{K}]$} \\
\hline$t$ & $=$ time & \\
\hline $\bar{t}$ & $=t / t_{0}$ & {$[-]$} \\
\hline$t_{0}$ & $=$ defined by Eq. $\left(15^{\prime}\right)$ & [s] \\
\hline$t_{1}$ & $=$ half cycle time & [s] \\
\hline$\overline{t_{1}}$ & $=t_{1} / t_{0}$ & {$[-]$} \\
\hline$v$ & $=$ interstitial velocity & {$[\mathrm{m} / \mathrm{s}]$} \\
\hline$v_{H}$ & $=v$ at high-pressure flow & {$[\mathrm{m} / \mathrm{s}]$} \\
\hline$v_{L}$ & $=v$ at low-pressure flow & {$[\mathrm{m} / \mathrm{s}]$} \\
\hline$z$ & $=$ position in the bed & {$[\mathrm{m}]$} \\
\hline $\bar{z}$ & $=z / L$ & {$[-]$} \\
\hline$\alpha$ & $=$ volumetric purge-to-feed ratio & {$[-]$} \\
\hline$\beta$ & $=$ defined by Eq. (14') & \\
\hline$\gamma$ & $=$ bed density & {$\left[\mathrm{kg} / \mathrm{m}^{3}\right]$} \\
\hline$\varepsilon$ & $=$ bed porosity & {$[-]$} \\
\hline$\rho_{\mathrm{g}}$ & $=$ gas density & {$\left[\mathrm{kg} / \mathrm{m}^{3}\right]$} \\
\hline$\rho_{\mathrm{s}}$ & $=$ adsorbent particle density & {$\left[\mathrm{kg} / \mathrm{m}^{3}\right]$} \\
\hline$\tau_{\mathrm{a}}$ & $=$ defined by Eq. $\left(8^{\prime}\right)$ & {$[-]$} \\
\hline$\tau_{\mathrm{b}}$ & $=$ defined by Eq. $\left(9^{\prime}\right)$ & {$[-]$} \\
\hline$\tau_{\mathrm{f}}$ & $=$ defined by Eq. $\left(10^{\prime}\right)$ & {$[-]$} \\
\hline$\tau_{\mathrm{H}}$ & $=$ defined by Eq. $\left(11^{\prime}\right)$ & {$[-]$} \\
\hline$\tau_{\mathbf{L}}$ & $=$ defined by Eq. $\left(12^{\prime}\right)$ & {$[-]$} \\
\hline$\tau_{\mathrm{W}}$ & $=$ defined by Eq. (13') & {$[-]$} \\
\hline
\end{tabular}

\section{Literature Cited}

1) Carter, J. W. and D. J. Barrett: Trans. Instn. Chem. Engrs., 51, 75 (1973).

2) Chan, Y. N. I., F. B. Hill and Y. W. Wong: Chem. Eng. Sci., 36, 243 (1981).

3) Doshi, K. J., C. H. Katira and H. A. Stewart: AIChE Symp. Ser., 67, No. 117, 90 (1971).

4) Kawazoe, K. and T. Kawai: Kagaku Kōgaku, 37, 288 (1973).

5) Kawazoe, K., Y. Takeuchi and S. Miyahara: "Adsorption and Ion Exchange," in Kagaku Kogaku Binran, pp. 847-910, Maruzen, Tokyo (1978).

6) Mitchell, J. E. and L. H. Shendalman: AIChE Symp. Ser., 69, No. 134, 25 (1973).

7) Shendalman, L. H. and J. E. Mitchell: Chem. Eng. Sci., 27, 1449 (1972).

8) Skarstom, C. W.: "Recent Development in Separation Science," Vol. 2, pp. 95-106, CRC Press, Cleveland, Ohio 
9) Turnock, P. H. and R. H. Kadlec: $A I C h E J ., 17,335$ (1971).

10) Weaver, K. and C. E. Hamrin, Jr.: Chem. Eng. Sci., 29, 1873 (1974).
11) Yagi, S. and D. Kunii: "Int. Development in Heat Transfer," p. 750, ASME, IME (1961).

12) Yagi, S. and D. Kunii and N. Wakao: "Int. Development in Heat Transfer," p. 742, ASME, IME (1961).

\title{
OUTPUT PROPERTIES OF IRON-THIONINE PHOTOGALVANIC CELL WITH FLOW-THROUGH ELECTRODES
}

\author{
MASAO SUDOH, TORU MURAKAMI AND TADASHI SHIROTSUKA \\ Department of Applied Chemistry, Waseda University, Tokyo 160
}

\begin{abstract}
To find a method to increase the output of the iron-thionine photogalvanic cell, experimental and theoretical research regarding a new type of cell with flow-through electrodes was carried out. The electrode-active species, leucothionine, is deactivated by the reaction of ferric ion and its own. If the active species reaches the electrode surface before its deactivation, an increase in output is expected. In the new system, leucothionine is produced in the illumination zone and transported to flow-through electrodes of carbon fiber felt by the flow of the solution.

The conversion efficiency of light intensity to electric power reached $0.236 \%$ at the maximum value. A theoretical analysis was then made of the mixed potentials of thionine and iron redox couples by using a two-phase model of the porous electrode.
\end{abstract}

\section{Introduction}

Recently, as a means of direct conversion of solar energy to electric energy, the photogalvanic cell discovered by Rabinowitch ${ }^{11)}$ has drawn much attention. Many experimental investigations have been made on the photochemical kinetics, ${ }^{7,8,14,18)}$ the solution components ${ }^{17)}$ and the electrode materials. $^{4,6,15,19,20)}$ Theoretical analyses were carried out on the electrochemical properties of the cell with two redox couples ${ }^{1-3)}$ and the usage of the membrane to separate electrode-active species. ${ }^{5)}$

Low values of conversion efficiency of light intensity to electric power, $3 \times 10^{-4 \%} \%,{ }^{10)} 10^{-3 \%} \%$ and $10^{-2 \%},{ }^{13)}$ were obtained. The highest value among the reports is $0.063 \%$ in the case of a multilayer cell with $\mathrm{SnO}_{2} / \mathrm{Pt}$ electrodes.

In comparison with the theoretical value, current efficiency is extremely low. ${ }^{14)}$ This result shows that almost none of the reduced thionine reaches the electrode surface during its life time as the electrodeactive species.

In the new method shown in this paper, the active substances are produced in the light illumination zone and transported to the flow-through electrode where the anodic reaction occurs. The increase in output of

Received March 15, 1982. Correspondence concerning this article should be addressed to $M$. Sudoh, now at Dept. of Chem. Eng., Shizuoka Univ., Hamamatsu 432. T. Murakami is now with Nippon Petrochemicals Co., Ltd., Tokyo 105 the photogalvanic cell is expected through the effective catching of the active species on the electrode surface. A theoretical analysis was made with the experimental results of $V_{O C}$ and $I_{S C}$ on the mixed potential of thionine and iron redox couples using a two-phase model of the porous electrode.

\section{Experimental Apparatus and Procedure}

\subsection{Photogalvanic cell with flow-through electrodes}

A schematic diagram of the experimental apparatus is shown in Fig. 1. The cell had electrodes of carbon fiber felt (F-210, Kureha Chem. Ind.) and a current feeder of platinum wire $\left(10^{-4} \mathrm{~m} \phi\right)$. The cell consisted of a polyvinyl chloride resin plate $\left(7 \times 10^{-3} \mathrm{~m}\right.$ thickness) held between two transparent glass plates $(5 \times$ $10^{-2} \mathrm{~m}$ width, $1 \mathrm{~m}$ length, $3 \times 10^{-3} \mathrm{~m}$ thickness). Two electrode sections downstream of the illumination zone were covered with dark sheets. Glass wool of a thickness of $10^{-2} \mathrm{~m}$ was packed between the two electrodes.

Light sources were high-pressure sodium lamps

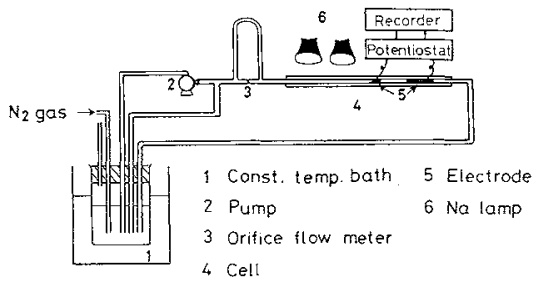

Fig. 1. Schematic diagram of apparatus. 